MATEC Web of Conferences 13, 05010 (2014)

DOI: $10.1051 /$ matecconf/ 20141305010

(C) Owned by the authors, published by EDP Sciences, 2014

\title{
Effect of Down Stand Depth Variation on Atriums Upper Balconies Smoke Contamination
}

\author{
Syed Ali Hasnain ${ }^{1 a}$, Mohammad ShakirNasif ${ }^{2}$, William Pao ${ }^{3}$ and Rafat Al-Waked ${ }^{4}$. \\ ${ }_{1,2,3}$ Mechanical Engineering Department, Universiti Teknologi PETRONAS, 31750 Tronoh, Malaysia. \\ ${ }^{4}$ Department of Mechanical Engineering, Prince Mohammad Bin Fahd University, P.O. Box 1664, Al- \\ Khobar 31952, Saudi Arabia
}

\begin{abstract}
In case of fire in an atrium, smoke produced is recognized as one of the major hazards for the occupants because of open spaces present in an atrium. The effect of varying the down stand depth at fire compartment on smoke contamination in upper balconies of an atrium has been investigated in this paper. Correlation to predict the smoke contamination in upper balconies of an atrium in the presence of $0.5 \mathrm{~m}$ deep down stand structure has also been developed. This correlation is compared with correlations developed for $1 \mathrm{~m}$ deep down stand and without down stand structure by past research. The comparison results showed that when the depth of down stand structure increase, smoke contamination in upper balconies of an atrium also increases. The results also showed that smoke contamination in upper balconies of an atrium decreases when the ratio of w/d increases. The comparison of correlations from $1 \mathrm{~m}$ and $0.5 \mathrm{~m}$ deep down stand showed that the difference in smoke contamination increases when $w / d<3$. By comparing the correlations from $0.5 \mathrm{~m}$ deep down stand and no down stand, there is very small difference in smoke contamination from both case but it is applicable for $\mathrm{w} / \mathrm{d}<3$.
\end{abstract}

\section{Introduction}

Fire is recognized as one of the enemy of human which causes loss of lives and properties. In case of fire, smoke and heat from the fire may kill the building occupants. It is generally found that during fire accident, the death percentage is mainly due to smoke inhalation instead of burning from the heat of fire. Hall [1] mentioned that in United States mostly victims of fire died from the smoke inhalation of toxic gases but not from the burns. Smoke has mainly three hazards which include its toxicity, visibility and thermal hazards. In case of fire in an atrium, smoke can spread easily to other floors because of its open spaces between the floors. Atrium in a shopping mall contains smoke extraction fan to extract the smoke from an atrium. But it is found that smoke may curl inward to the upper balconies of an atrium and cause smoke contamination of the upper balconies of an atrium.

Past research [2-3] found that building structure like balcony breath, width of fire compartment opening and fire size may affect the smoke contamination in upper balconies of an atrium. Although, down stand structure can be seen in almost every shop or office of the shopping mall to display its trade name but past research only investigated the effect of down stand structure on air entrainment. There is very limited research available which investigated the effect of down stand structure on

aCorresponding author: alihasnain833@yahoo.com

This is an Open Access article distributed under the terms of the Creative Commons Attribution License 2.0, which permits unrestricted use, distribution, and reproduction in any medium, provided the original work is properly cited. 
smoke contamination in upper balconies of an atrium. Hasnain et al. [4] investigated the effect of down stand depth of $1 \mathrm{~m}$ on smoke contamination in upper balconies of an atrium. They suggested that the presence of $1 \mathrm{~m}$ down stand increases the smoke contamination in upper balconies of an atrium as compared to without down stand structure at fire compartment opening.

The objective of this paper is to investigate the effect of $0.5 \mathrm{~m}$ deep down stand on smoke contamination in upper balconies of an atrium and to compare it with the down stand of $1 \mathrm{~m}$ depth and without down stand.

\section{Model Development}

Fire Dynamic Simulator, (FDS) software is used to numerically investigate the effect of varying depth of down stand structure on smoke contamination in upper balconies of an atrium. In this study the developed model consists of five storey atrium with $0.5 \mathrm{~m}$ deep down stand structure as shown in the Figure 1. The width of fire compartment opening $w$, balcony breath $b$ and fire size are varied in each numerical simulation.

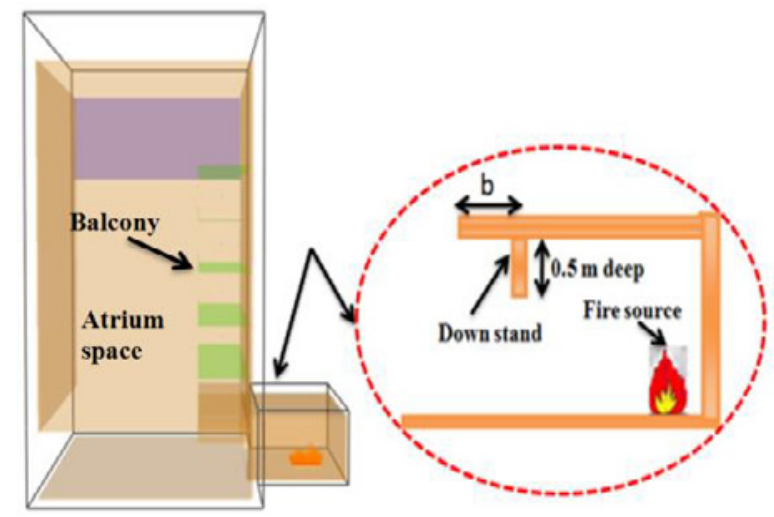

Figure 1. FDS model with $0.5 \mathrm{~m}$ deep down stand

Mesh size of $200 \mathrm{~mm}$ is used because it meets the criterion describe by Harrison [5] which is shown in the Eq. (1) and (2). The dimensions for the domain of the five storey atrium are $24 \mathrm{~m} \mathrm{X} 21.6$ $\mathrm{m} \mathrm{X} 36 \mathrm{~m}$.For the fire compartment the dimensions are $12 \mathrm{~m} \mathrm{X} 9 \mathrm{~m} \mathrm{X} 6 \mathrm{~m}$. The total number of grid cells in an atrium and in the fire compartment are 2332800 and 81000 respectively.

$$
\begin{gathered}
n^{*}=\frac{D_{\text {spill }}^{*}}{\Delta X} \geq 0.9 \\
D^{*}=\left(Q_{c} / w / \rho C_{p} T \sqrt{g}\right)^{2 / 3}
\end{gathered}
$$

Where $D^{*}$ is characteristic length of plume for determining the grid size $(\mathrm{m}), n^{*}$ is coefficient for determining the grid size, $\Delta X$ is grid dimension in x-axis, $Q_{\mathrm{c}}$ is convective heat flow layer below spill edge, $\rho$ is air density at ambient condition, $C_{p}$ is specific heat, $T$ is absolute temperature and $\mathrm{g}$ is gravity acceleration.

In the multi storey atrium fire can take place in any floor of an atrium. For design purpose it is appropriate approach to take the worst case. Morgan et al. [6] suggested that the worst case in fire accident, if the fire occurs in the lowest level of the adjacent space of an atrium. The reason behind considering lowest level fire, because plume flow distance to the top of the atrium will be longer and will entrain large amount of air as compared to other possibilities (fires at other floors). Morgan et al. [6] also mentioned that steady state design fire for shops are $5 \mathrm{MW}$ in the presence of standard response sprinkler. Therefore the maximum fire size in this numerical study is about 4.8 MW.

Hasnain et al. [13] has already performed the validation of the FDS model against past research. Therefore the validation of the model is not presented in this paper. 


\section{Results and Discussion}

The results are presented in the form of correlation to predict the smoke contamination in upper balconies of an atrium. The correlation developed from $0.5 \mathrm{~m}$ deep down stand structure is compared with correlation developed for $1 \mathrm{~m}$ deep [4] and no down stand structure [3]. In the correlation depth of the plume below spill edge $d$ and height of smoke contamination above balcony $1 H$ are obtained from FDS results, while width of fire compartment opening $w$ and balcony breadth $b$ are building structure. As temperature of the smoke is also an important parameter to predict the smoke contamination. So, comparison of temperature along the balcony edges and inside each balcony is also presented in this section.

\subsection{Comparison of Temperature}

For the developed model with $0.5 \mathrm{~m}$ deep down stand structure, temperature along the balcony edge obtained from FDS found to be lower than that of $1 \mathrm{~m}$ deep down stand which was recorded by Hasnain et al. [4] (as shown in Figure 2). The difference is significantly high along balcony edge of balcony 2 and 3. As Tan et al. [2] mentioned, if the balcony has temperature $10^{\circ} \mathrm{C}$ above the ambient temperature then the smoke will contaminate the balcony. Therefore by looking towards the temperature curves along the balcony edges (as shown in Figure 2), it shows that the presence of smoke in case of $1 \mathrm{~m}$ deep down stand is more as compared to $0.5 \mathrm{~m}$ deep down stand structure

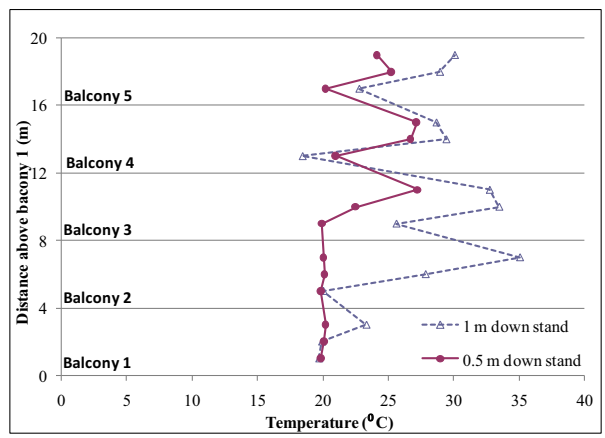

Figure 2. Temperature along the balcony edges

Figure 3 shows temperature inside each balcony for both down stand depth of $1 \mathrm{~m}$ and $0.5 \mathrm{~m}$. It shows that temperature inside each balcony for $1 \mathrm{~m}$ deep down stand is higher than for $0.5 \mathrm{~m}$ deep down stand.

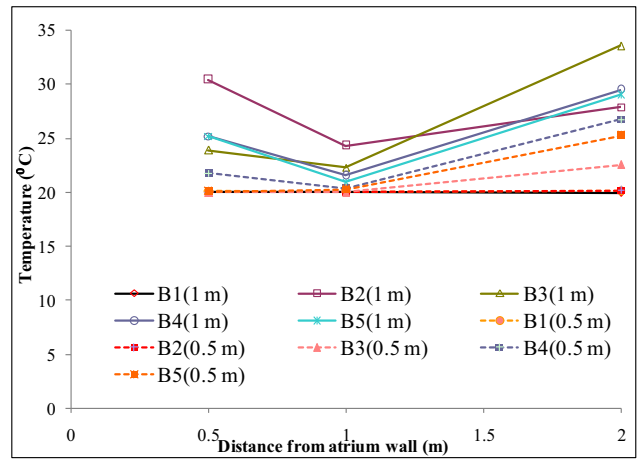

Figure 3. Temperature in each balcony

In Figure 3 each balcony is shown with letter B and a numeric value for balcony number and depth of down stand. Numeric value outside the brackets is used for balcony number and the numeric value inside the brackets is used for depth of down stand. For example Balcony 2 for $0.5 \mathrm{~m}$ deep down stand 
is shown as B2 $(0.5 \mathrm{~m})$ as seen in Figure 3 As temperature in each balcony for $1 \mathrm{~m}$ deep down stand is higher than that of $0.5 \mathrm{~m}$ deep down stand. Therefore, smoke contamination in upper balconies of an atrium for $1 \mathrm{~m}$ deep down stand is also expected to be more as compared to $0.5 \mathrm{~m}$ deep down stand.

\subsection{Comparison of Correlation}

In order to predict the height of smoke contamination in upper balconies of an atrium, a correlation has been developed in the presence of $0.5 \mathrm{~m}$ deep down stand at the fire compartment opening. This correlation is used to make the comparison with other correlations (correlation from without down stand and $1 \mathrm{~m}$ deep down stand [3-4]) which have been developed previously.

By comparing the correlation of $0.5 \mathrm{~m}$ deep down stand and without down stand structure at the fire compartment opening, it is shown in the Figure 4 that the effect of $0.5 \mathrm{~m}$ deep down stand on smoke contamination of the upper balconies of an atrium is minor. From the correlation, it is found that for $0.5 \mathrm{~m}$ deep down stand there is slight increase in the smoke contamination in the upper balconies of an atrium as compared to without down stand structure but this is valid for $w / d>3$. However it is also shown in Figure 4 that smoke contamination will remain same for both $0.5 \mathrm{~m}$ deep down stand and no down stand at $w / d<3$.

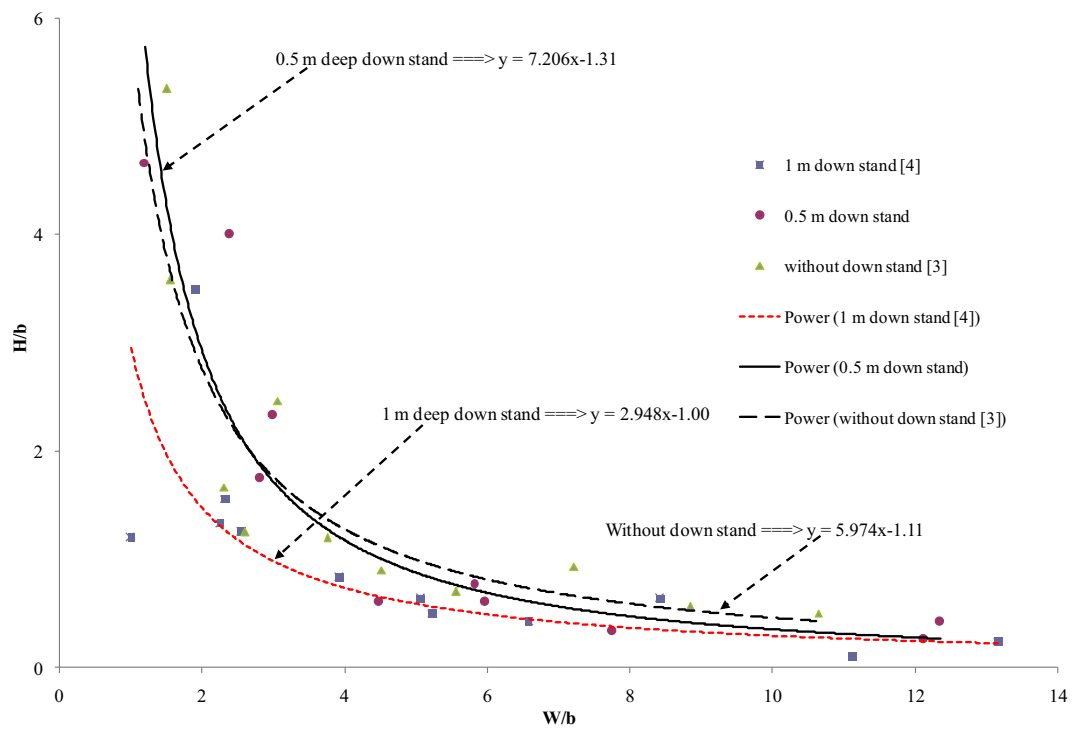

Figure 4. Comparison of three correlations obtained from different building structure

By comparing $1 \mathrm{~m}$ and $0.5 \mathrm{~m}$ deep down stand structure, it is found from Figure 4 that there is more smoke contamination for $1 \mathrm{~m}$ deep down stand as compared to $0.5 \mathrm{~m}$ deep down stand structure. The difference in smoke contamination height for both depth of down stand $(1 \mathrm{~m}$ and $0.5 \mathrm{~m})$ would be low if the ratio of $w / d$ is high. As shown in the Figure 4 that at higher value of w/d (more then 10), the difference in smoke contamination height in both depth of down stand become very small. However, when the value of $w / d$ is less than 10 then the difference in smoke contamination between $1 \mathrm{~m}, 0.5 \mathrm{~m}$ deep down stand and no down stand become significant.

It can also be seen in Table 1 that in almost all simulations the height of smoke contamination for $1 \mathrm{~m}$ deep down stand is lower than that of $0.5 \mathrm{~m}$ deep down stand which shows that the smoke contamination in upper balconies of an atrium for $1 \mathrm{~m}$ deep down stand is more than that of $0.5 \mathrm{~m}$ deep down stand. 
Table 1. Comparison of smoke contamination height above balcony 1 and depth of the plume below spill edge

\begin{tabular}{|c|c|c|c|c|c|c|c|c|}
\hline \multicolumn{4}{|c|}{ Parameters } & \multicolumn{2}{c|}{$1 \mathrm{~m}$ deep } & \multicolumn{2}{c|}{$0.5 \mathrm{~m}$ deep } & \multicolumn{2}{c|}{ Change (\%) } \\
\hline Case & $\mathrm{b}(\mathrm{m})$ & $\mathrm{w}(\mathrm{m})$ & $\mathrm{H}(\mathrm{m})$ & $\mathrm{d}(\mathrm{m})$ & $\mathrm{H}(\mathrm{m})$ & $\mathrm{d}(\mathrm{m})$ & $\Delta \mathrm{H}(\%)$ & $\Delta \mathrm{d}(\%)$ \\
\hline 1 & 5 & 10 & 1.2 & 0.76 & 2.1 & 0.81 & 42.86 & 6.17 \\
\hline 2 & 5 & 10 & 0.50 & 0.9 & 1.30 & 0.83 & 61.54 & 8.33 \\
\hline 3 & 5 & 6 & 2.10 & 0.912 & 3.00 & 1.01 & 30.00 & 9.25 \\
\hline 4 & 5 & 2 & 7.8 & 0.863 & \multicolumn{3}{c|}{ No smoke contamination } \\
\hline 5 & 3 & 8 & 1.9 & 0.95 & 1 & 1.03 & 47.37 & 7.95 \\
\hline 6 & 3 & 6 & 1.9 & 1.184 & 2.30 & 1.34 & 17.39 & 11.44 \\
\hline 7 & 3 & 4 & 2.5 & 1.02 & 7 & 1.34 & 64.29 & 23.88 \\
\hline 8 & 2 & 6 & 1 & 1.148 & 1.2 & 1.43 & 16.67 & 19.44 \\
\hline 9 & 2 & 4 & 2.5 & 1.57 & 3.50 & 1.52 & 28.57 & 3.18 \\
\hline 10 & 2 & 2 & 7 & 1.05 & \multicolumn{3}{c|}{ No smoke contamination } \\
\hline 11 & 1.5 & 4 & 2 & 1.77 & 6 & 1.68 & 66.67 & 5.08 \\
\hline 12 & 1.5 & 2 & 1.8 & 2 & 7 & 1.847 & 74.29 & 7.65 \\
\hline
\end{tabular}

\section{Conclusion}

This paper provides comparison of smoke contamination in upper balconies of an atrium in the presence of two down stand depths $(1 \mathrm{~m}$ and $0.5 \mathrm{~m}$ ) and without down stand. The comparison of three correlations shows that when depth of down stand increases the smoke contamination in upper balconies of an atrium will also increase. For $1 \mathrm{~m}$ deep down stand the effect of down stand depth on smoke contamination in upper balconies is significantly high at lower value of $w / d$. However, when the value of $w / d>3$, the effect of down stand depth on smoke contamination in upper balconies of an atrium become minor. For $w / d<3$, the smoke contamination will be same for $0.5 \mathrm{~m}$ deep down stand and no down stand. But when $w / d>3$ then there will be small increase in smoke contamination in 0.5 $\mathrm{m}$ deep down stand as compared to no down stand.

\section{Acknowledgement}

The authors would like to acknowledge Universiti Teknologi PETRONAS for providing financial assistance under Graduate Assistance scheme (GA) to carry out this research.

\section{References}

1. J. R. Hall, NFPA, Fire Anal. and Research Division, MA, (2001).

2. F. Tan, R. Harrison and M. Spearpoint, J. of F. Sc., vol. 28, pp. 313-336, (2010).

3. C. L. Ho, F. Eng. Res. Rep., University of Canterbury, (2010).

4. S. A. Hasnain, M. S. Nasif, W. Pao and R. Al-Waked, App. Mech. and Mat., vol. 465-466, pp. 480-484, (2014).

5. R. Harrison, PhD thesis, University of Canterbury, (2009).

6. H. P. Morgan, B. K. Ghosh, G. Garrad, R. Pamlitschka, J-C De Smedt and L. R. Schoonbaert, Const. Res. Com. Ltd. London, UK:,(1999). 